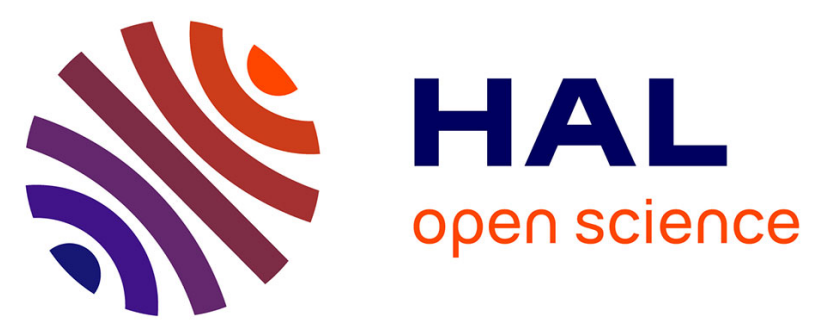

\title{
Transverse compressive properties of natural fibers determined using micro mechatronic systems and 2D full-field measurements
}

Vincent Placet, Mélissa Blot, Tine Weemaes, Hugo Bernollin, Guillaume Laurent, Fabien Amiot, Cédric Clevy, Johnny Beaugrand

\section{To cite this version:}

Vincent Placet, Mélissa Blot, Tine Weemaes, Hugo Bernollin, Guillaume Laurent, et al.. Transverse compressive properties of natural fibers determined using micro mechatronic systems and 2D full-field measurements. 4th International Conference on Natural Fibers - Smart Sustainable Materials, ICNF 2019, Jul 2019, Porto, Portugal. pp.303 - 308, 10.1016/j.matpr.2020.01.383 . hal-03020523

\section{HAL Id: hal-03020523 \\ https://hal.science/hal-03020523}

Submitted on 22 Nov 2021

HAL is a multi-disciplinary open access archive for the deposit and dissemination of scientific research documents, whether they are published or not. The documents may come from teaching and research institutions in France or abroad, or from public or private research centers.
L'archive ouverte pluridisciplinaire $\mathbf{H A L}$, est destinée au dépôt et à la diffusion de documents scientifiques de niveau recherche, publiés ou non, émanant des établissements d'enseignement et de recherche français ou étrangers, des laboratoires publics ou privés. 


\title{
Transverse Compressive Properties of Natural Fibers Determined using Micro Mechatronic Systems and 2D Full-Field Measurements
}

\author{
Vincent Placet ${ }^{\mathrm{a} *}$, Mélissa Blot ${ }^{\mathrm{a}}$, Tine Weemaes ${ }^{\mathrm{a}}$, Hugo Bernollin ${ }^{\mathrm{a}}$, Guillaume Laurent ${ }^{\mathrm{a}}$, \\ Fabien Amiot ${ }^{\mathrm{a}}$, Cédric Clévy ${ }^{\mathrm{a}}$, and Johnny Beaugrand ${ }^{\mathrm{b}}$ \\ ${ }^{a}$ FEMTO-ST Institute, Université Bourgogne Franche-Comté, Besançon, France \\ ${ }^{b}$ Biopolymères Interactions Assemblages (BIA), INRA, Nantes, France
}

\begin{abstract}
The literature focusing on the transverse mechanical properties of single fibers is very sparse compared to those related to longitudinal properties. An original characterization method is proposed herein, relying on a micro mechatronics device to implement a transverse compression test which is monitored using 2D full-field measurements. This is shown to allow for the identification of the transverse elastic properties of a single fiber. The method is used, at first, on a bio-based polymer monofilament (PA11) which is assumed to have regular and controlled dimensions and geometry. The transverse elastic modulus is identified to be equal to approximately $1500 \mathrm{MPa}$ and the longitudinal modulus $2150 \mathrm{MPa}$. The proposed method is then used to investigate the transverse compressive behavior of contrasted natural fibers, such as beard hair (protein-based) and sisal fibers (polysaccharidesbased) which have more complex shape and/or internal structure. This paper gives for the first time the compressive force displacement curves as well as the monitoring of the shape of the cross-section during the loading.
\end{abstract}

Keywords: Transverse compression; monofilaments; natural fibers; micro mechatronics; full-field measurements

\section{Introduction}

One of the main shortcomings of the current knowledge on plant fibers is related to their transverse mechanical properties. To the best of the author's knowledge, no data determined by direct methods can be found in the literature. Only values determined by back-calculation from tensile tests realized in the transverse direction of unidirectional composite materials [1] are available. More generally, literature on the transverse mechanical properties of synthetic monofilaments is sparse compared with the voluminous data on their longitudinal properties. In this study, we propose to develop an experimental device and methodology to accurately determine the transverse compressive properties of polymeric monofilaments and natural fibers. This compression experimental test is commonly called as «Brazilian » test or as Single Fiber Transverse Compression Test (SFTCT) and has been proposed and developed since the 60's [2]. It has been mainly applied on single synthetic fibers and textile fibers assemblies, so far. In most of the works, the fibers and monofilaments are assumed as perfectly cylindrical and made of elastic isotropic or transversely isotropic material. The problem is treated as for two semi-infinite solids in contact (Hertz) under conditions of plane strain. Literature points out that conducting such experiments on small diameter polymeric fibers is really challenging. Indeed, their small diameter and low modulus make the test specimen very compliant per length unit. The tests require also an accurate alignment and measurement of platen displacement. In addition, this experiment is very sensitive to the geometry of the contact between fiber and platen and consequently on variations in the fiber diameter. The transverse compressive modulus is generally identified by inverse method using analytical models [3,4]. For 
anisotropic materials, the model is sensitive to the other elastic properties (longitudinal elastic modulus and major Poisson's ratio). To cope with these difficulties, an original methodology and the associated device were developed. It comprises a set-up based on micro mechatronics system and 2D full-field strain measurements at the microscale.

\section{Experimental set-up}

Figure 1 shows a schematic representation and corresponding pictures of the original experimental set-up proposed to implement the Single Fibre Transverse Compression Test (SFTCT). It relies on a microelectromechanical system (MEMS) device and 2D full-field measurements at the microscopic scale. The experimental device thus consists of an actuator connected to a compliant sensor which end constitutes the upper compression platen, a fixed lower platen and an optical system for observing the cross-section of the fiber. The actuator and the lower platen are connected to high-precision 4-axis micro positioning robot for adjusting their initial position and thus ensure a proper alignment and parallelism of the compression platens. The measurement of the platen-relative displacement and contact force on the fibers relies both on a compliant micro mechatronic system that has been specifically designed for the purpose of the study. The system comprises three complementary elements: (1) a passive micromechanical compliant structure whose design relies on a compliant translational-joint (CT-joint) configuration that strongly limits unwanted motions out of the measurement direction. When an external force is applied to the tip of the sensor (Fig. 1), a relative displacement is induced between two parts in the middle; (2) two periodic patterns sputtered onto these two parts; (3) a vision microscope to track the relative motions of the patterns and a Fourier-based transform enables to estimate the relative displacement between the two parts [5,6]. Based on this principle, it is then possible to estimate the external force applied to the sensor (knowing the stiffness previously calibrated). The basic principle of this sensor leads to a unique range-to-resolution ratio with a full measurement range of about $300 \mathrm{mN}$ and a precision of about $14 \mu \mathrm{N}$. The strains at the cross-section at the end of the fiber are determined using digital image correlation (DIC). The integrated digital image correlation is implemented in a homemade (Octave-based) correlation software.

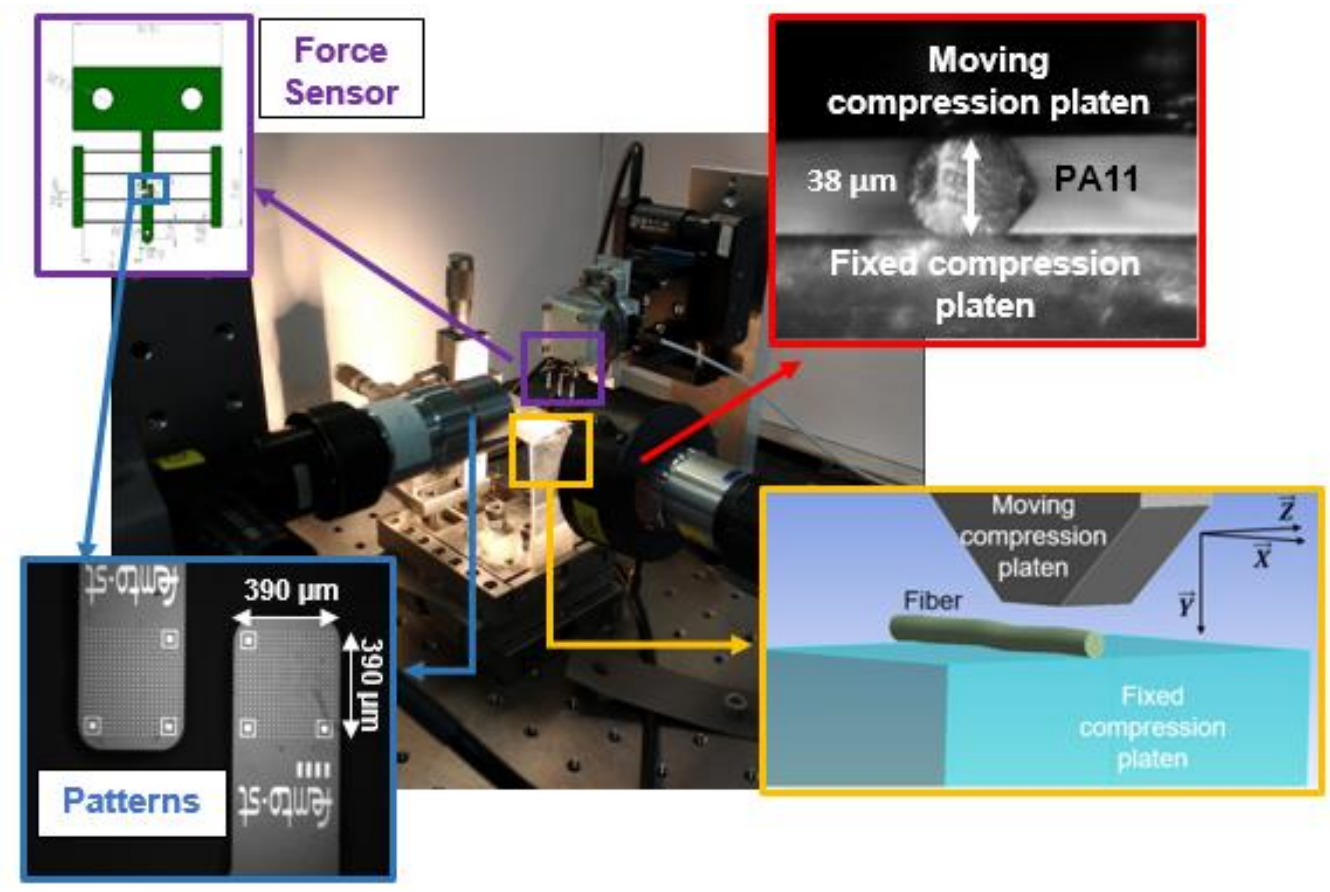

Fig. 1. SFTCT experimental configuration including a 4 axis micropositiong robot, a micro mechatronic force sensor, two cameras and $2 \mathrm{XYZ}$ manual micropositioning systems. 
The transverse elastic properties are then determined using two complementary approaches.

The first one is based on the analytical model proposed by Abdul Jawad and Ward [3]. The transverse modulus ( $\left.\mathrm{E}_{\mathrm{T}}\right)$ is determined using the force-displacement curve, the initial fiber diameter, the longitudinal modulus ( $\left.E_{\mathrm{L}}\right)$, the major Poisson's ratio $\left(v_{\mathrm{LT}}\right)$, the minor Poisson's ratio $\left(v_{\mathrm{TT}}\right)$ and an inverse method based on a minimization algorithm and the analytical formulae (Eq.1). This expression was written for a transversely isotropic elastic material being compressed between two infinitely rigid plates and considering a change in curvature of the geometry at the contact zone in agreement with the Hertz solution.

with $\mathrm{U}_{1}$ the transverse displacement, $\mathrm{F}$ the applied load normalized by the compressed length, $\mathrm{R}$ the radius of the fiber,

$$
\begin{gathered}
U_{1}=-\frac{4 F}{\pi}\left(\left(S_{11}-\frac{S_{13}^{2}}{S_{33}}\right)\left(\operatorname{arcsinh}\left(\frac{R}{b}\right)+0.69\right)\right)+\frac{2 F}{\pi}\left(S_{11}+S_{12}-\frac{2 S_{13}^{2}}{S_{33}}\right) \\
-\frac{4 F}{\pi}\left(\left(S_{12}-\frac{S_{13}^{2}}{S_{33}}\right)\left(\frac{R}{b}\right)\left(\sqrt{1+\left(\frac{R}{b}\right)^{2}}-\frac{R}{b}\right)\right)
\end{gathered}
$$

$\mathrm{S}_{\mathrm{ii}}$ the constants of the compliance matrix expressed as following:

$$
S_{11}=\frac{1}{E_{T}} ; S_{12}=-\frac{v_{T T}}{E_{T}} ; S_{13}=-\frac{v_{T L}}{E_{T}} ; S_{33}=\frac{1}{E_{L}}
$$

$\mathrm{b}$ is the half-width of the contact defines in agreement with the Hertz solution:

$$
\mathrm{b}=\sqrt{\left(\frac{4 F R}{\pi}\right)\left(S_{11}-\frac{S_{13}^{2}}{S_{33}}\right)}
$$

The second method is based on the displacement fields measured at the end of the fiber on its cross-section, an integrated formulation based on a description by Kolosov- Muskhelishvili potentials [7], the measured load and the fiber diameter. It allows the determination of the transverse modulus and of the minor Poisson's ratio. Considering a point $z=x+i y$ of the complex plane, the displacement $V_{B}=V_{B x}+i V_{B y}$ reads:

$$
V_{B}=\frac{F}{4 \pi \mu}\left[\kappa\left(\frac{Z}{R}-\log \left(\frac{R+z}{R-z}\right)\right)-\frac{Z}{R}+\frac{R+z}{R+\bar{z}}-\frac{R-z}{R-\bar{z}}-\log \left(\frac{R+\bar{z}}{R-\bar{z}}\right)\right]
$$

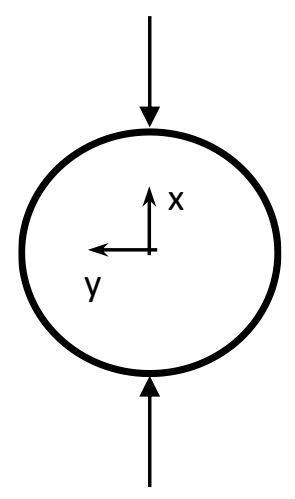

The displacement is thus sought as its expansion onto the basis obtained by concatenating the rigid body motions (one rotation and two translations) with the two functions: 


$$
\begin{gathered}
f_{k}=\frac{z}{R}-\log \left(\frac{R+z}{R-z}\right) \\
f_{\mu}=-\frac{z}{R}+\frac{R+z}{R+\bar{z}}-\frac{R-z}{R-\bar{z}}-\log \left(\frac{R+\bar{z}}{R-\bar{z}}\right)
\end{gathered}
$$

The associated degrees of freedom are (Eq. 7) and (Eq. 8) respectively:

$$
\begin{gathered}
\frac{\kappa F}{4 \pi \mu} \\
\frac{F}{4 \pi \mu}
\end{gathered}
$$

For plane stress:

$$
\kappa=\frac{3-v}{1+v}
$$

The coefficients $\mu$ and $v$ are thus obtained from linear regressions between the measured quantities.

\section{Validation of the proposed method on a synthetic fiber}

The original SFTCT set-up and methods were experimented, at first, on a synthetic fiber, a polyamide 11 monofilament (Rilsan ${ }^{\circledR}$ LMFO) with an average diameter of $37.3 \pm 1.26 \mu \mathrm{m}$. Figures 2 shows the typical loaddisplacement curve obtained when the fiber is submitted to a monotonic load-unload path at a displacement rate of $0.015 \mu \mathrm{m} . \mathrm{s}^{-1}$.

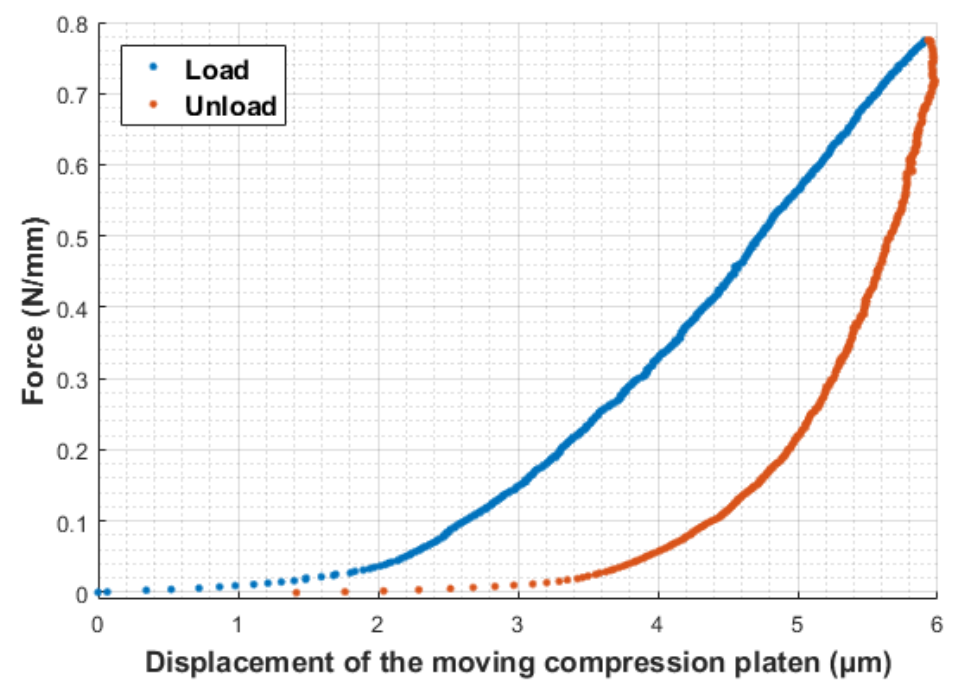

Fig. 2. Experimental load/unload - displacement curves, PA11 monofilament 
The transverse compression of this polymer monofilament exhibited the expected non-linear and dissipative behavior as reported in literature [1-4]. The displacement fields were also successfully measured using DIC at the microscale. Using the DIC data and the integrated formulation based on a description by Kolosov-Muskhelishvili potentials, the following elastic properties were identified for the PA11 monofilament from linear regressions between the measured quantities (Fig. 3): $\mu=758 \mathrm{MPa}\left(\mathrm{E}_{\mathrm{T}}=1620 \mathrm{MPa}\right)$ and $\nu_{\mathrm{TT}}=0.07$
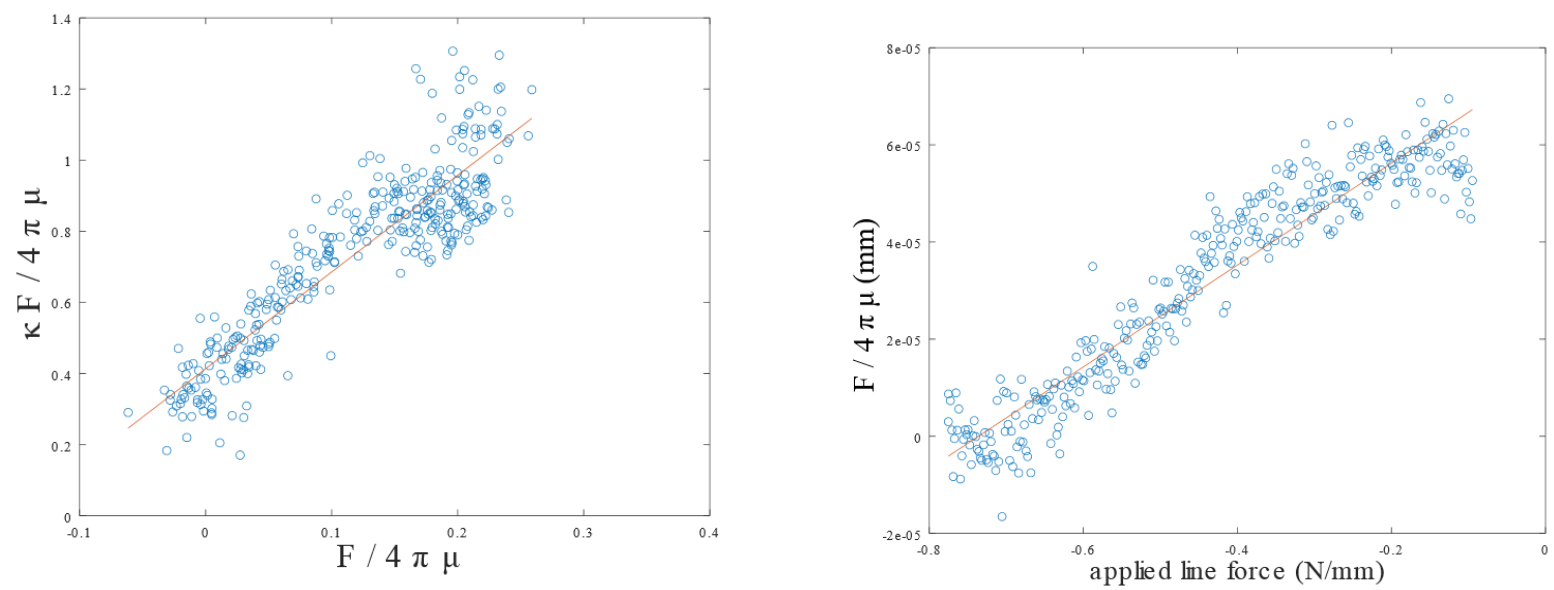

Fig. 3. Results obtained from the integrated DIC

The transverse modulus was also identified using the Abdul Jawad's model [3]. Some of the other elastic properties (i.e. $\mathrm{E}_{\mathrm{L}}, v_{\mathrm{TT}}$ and $v_{\mathrm{LT}}$ ) are necessary to do so. The value of the minor Poisson's ratio identified using the KolosovMuskhelishvili's model was considered here $\left(v_{\mathrm{TT}}=0.07\right)$. The value of the major Poisson's ratio was arbitrarily fixed at a value of 0.4 , based on the values given by the material provider for the Poisson's ratio of the bulk PA11 considered as isotropic material. The longitudinal modulus was determined using the Single Fiber Tensile Test (SFTT, Fig. 4) and the Fiber Bundle Tensile Test (FBTT, Fig.5). In this work, a fiber bundle is considered as a collection of several fibers connected in parallel and with both ends clamped to support [6]. For simplicity, the fibers are assumed to be of equal length, to have the same elastic constant and to be perfectly aligned.

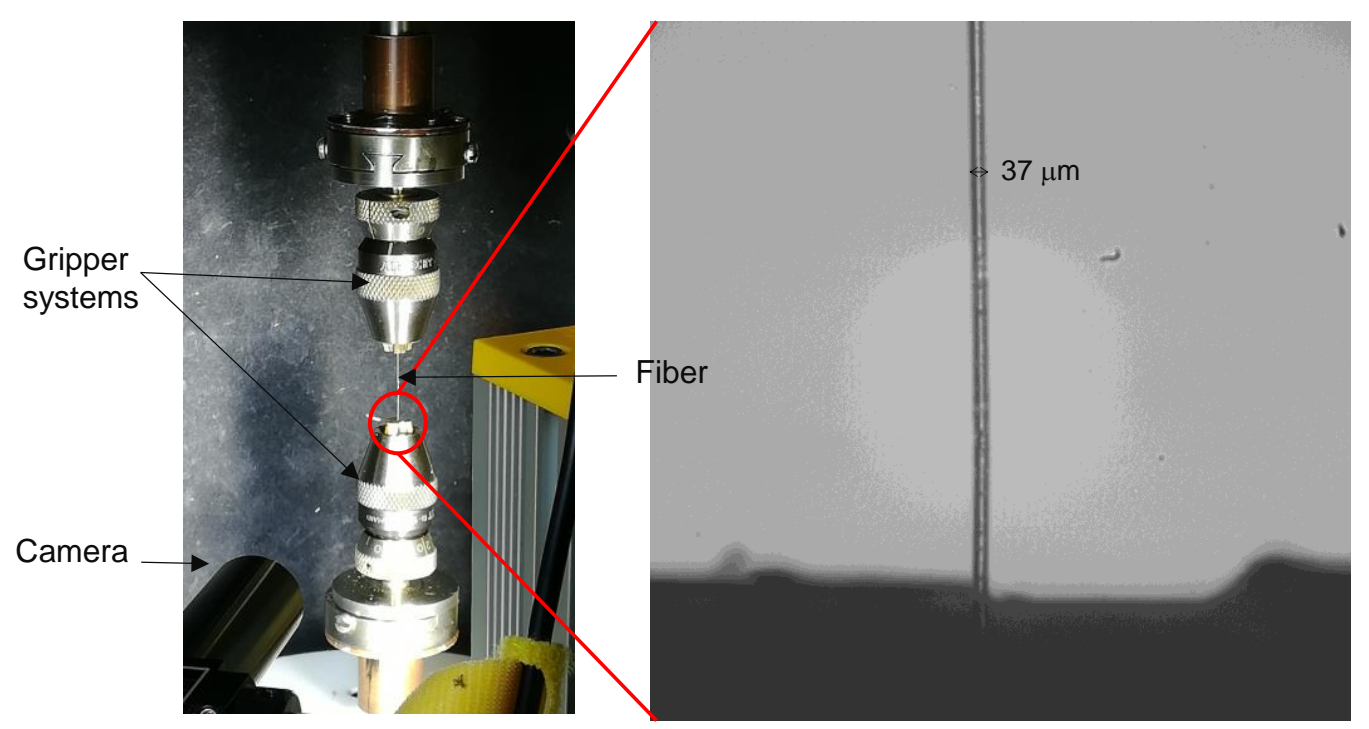

Fig. 4. (left) SFTT experimental configuration; (right) optical image of bottom part of the fiber. 


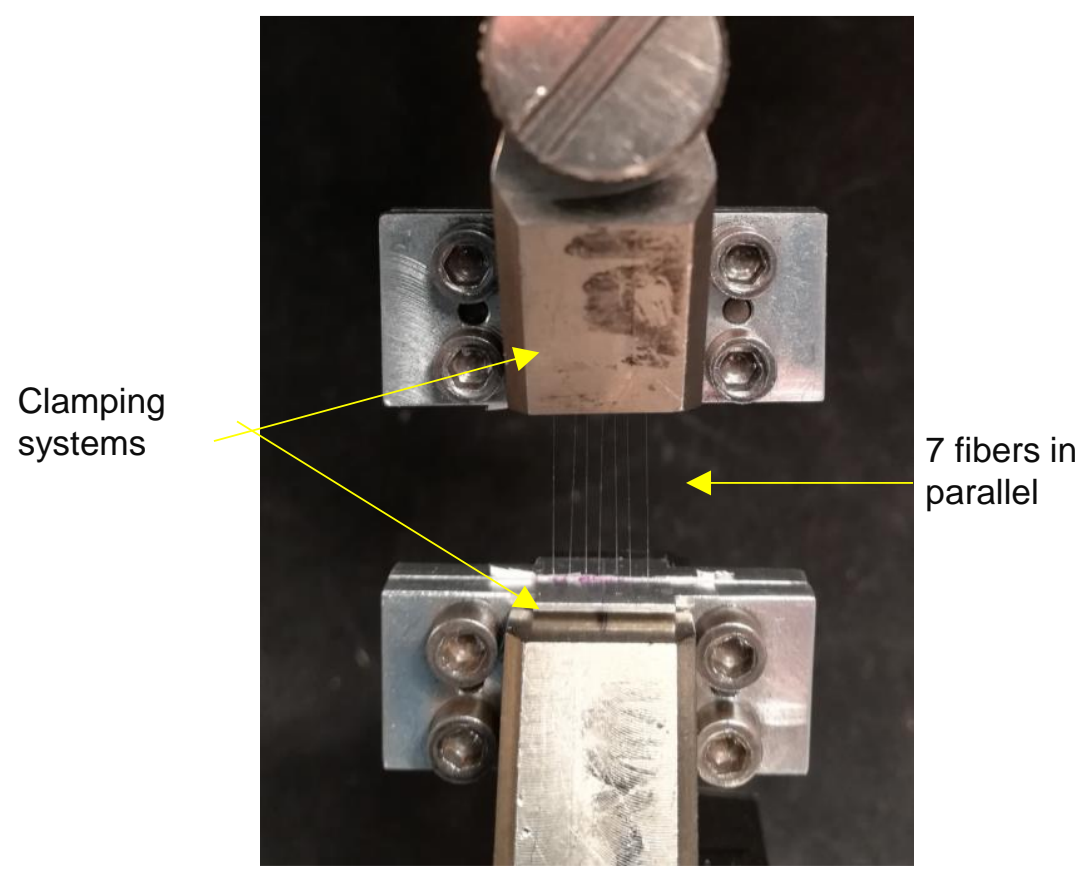

Fig. 5. FBTT experimental configuration: 7 PA11 monofilaments of $10 \mathrm{~mm}$ in length mounted in parallel.

15 fibers were tested using the SFTT test. The results are presented in Figure 6. A large scattering is observed. The obtained values are comprised between $1445 \mathrm{MPa}$ and $2700 \mathrm{MPa}$. The mean value, equal to $2155 \mathrm{MPa}$, is consistent with the one obtained using FBTT test (2180 MPa, see Table 1).

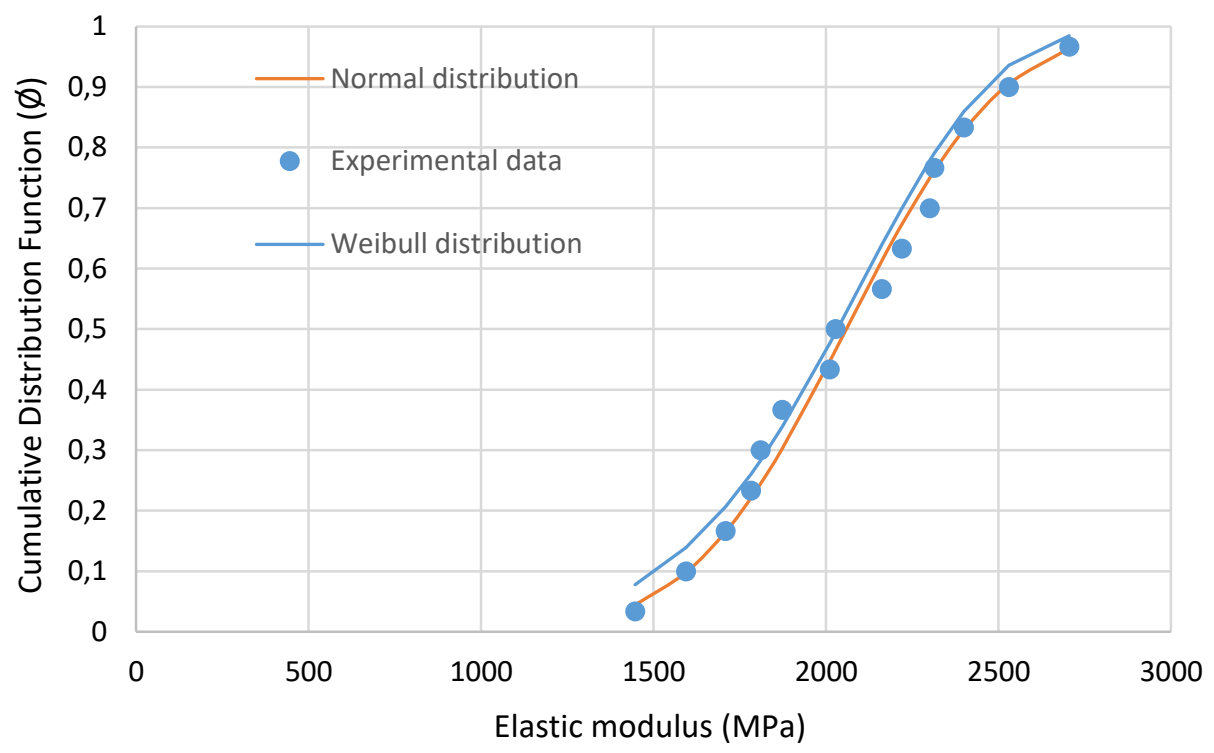

Fig. 6. Cumulative distribution function of the E-modulus determined on PA11 using SFTT 
Table 1. Tensile modulus of the tested PA11 fibers.

\begin{tabular}{lc}
\hline Type of test & Tensile modulus (MPa) \\
\hline SFTT & $2155 \pm 359$ \\
Mean value \pm standard deviation & 2180 \\
FBTT & \\
Mean value &
\end{tabular}

Using these values, the experimental curve obtained under transverse compression was fitted using the Abdul Jawad's model. The results are plotted in Figure 7. A good agreement is obtained between the model and the experiment. The identified value for the transverse modulus is $1395 \mathrm{MPa}$. The order of magnitude is similar to the one obtained using the Kolosov- Muskhelishvili's model (1620 MPa). These results point out the anisotropy of the elastic properties of the PA11 at the scale of the monofilaments. An anisotropy factor comprised between 0.65 and 0.8 was recorded for the tested monofilaments. These values can be compared to the results obtained by Phoenix and Skelton [9] on a Nylon monofilament ( $15 \mu \mathrm{m}$ nominal diameter). They reported a longitudinal and transverse moduli of $3600 \mathrm{MPa}$ and 400 MPa respectively. For a PA 6.6 (400 $\mu \mathrm{m}$ diameter), Stamoulis et al. [10] obtained $2500 \mathrm{MPa}$ and $163 \mathrm{MPa}$.

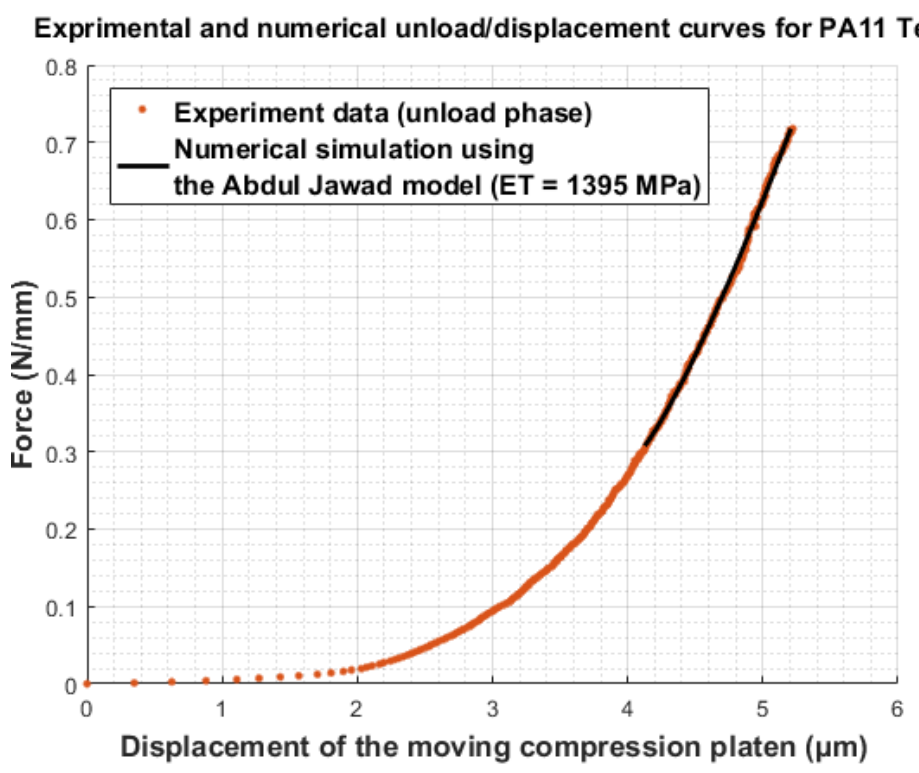

Fig. 7. Experimental and numerical unload/displacement curves

\section{Investigation of the transverse compressive behavior of natural fibers using the proposed method}

After evaluating and validating the proposed set-up and method at the scale of synthetic monofilaments, some feasibility tests were realized at the scale of animal and plant fibers. Such experiments are even more challenging in the sense that natural fibers present generally a complex and irregular shape as well as a heterogeneous microstructure [11-13].

Fig. 8 shows the experimental configuration used to test a beard hair. This one has an elliptical cross-section shape with minor and major diameters of about $90 \mu \mathrm{m}$ and $180 \mu \mathrm{m}$, respectively. This hair was submitted to a monotonic load-unload compressive test up to approximately $0.55 \mathrm{~N} . \mathrm{mm}^{-1}$ (see Fig. 9, on left). Three different stages can be observed on the response curves. In the first stage, a quite large displacement is run (several tens of microns) for a slight increasing force. During this step, the progressive alignment of the initially pre-deformed hair is observed. In the second stage, the rotation around the main axis was observed until the main axis of the hair's cross-section was 
positioned parallel to the compressive plate axis. A total force of $0.3 \mathrm{~N} . \mathrm{mm}^{-1}$ was finally necessary to correctly position the hair between the platens and then start the pure transverse compressive test. The transverse compressive stiffness is then approximately $0.314 \mathrm{~N} \cdot \mathrm{mm}^{-1} \cdot \mu \mathrm{m}^{-1}$.

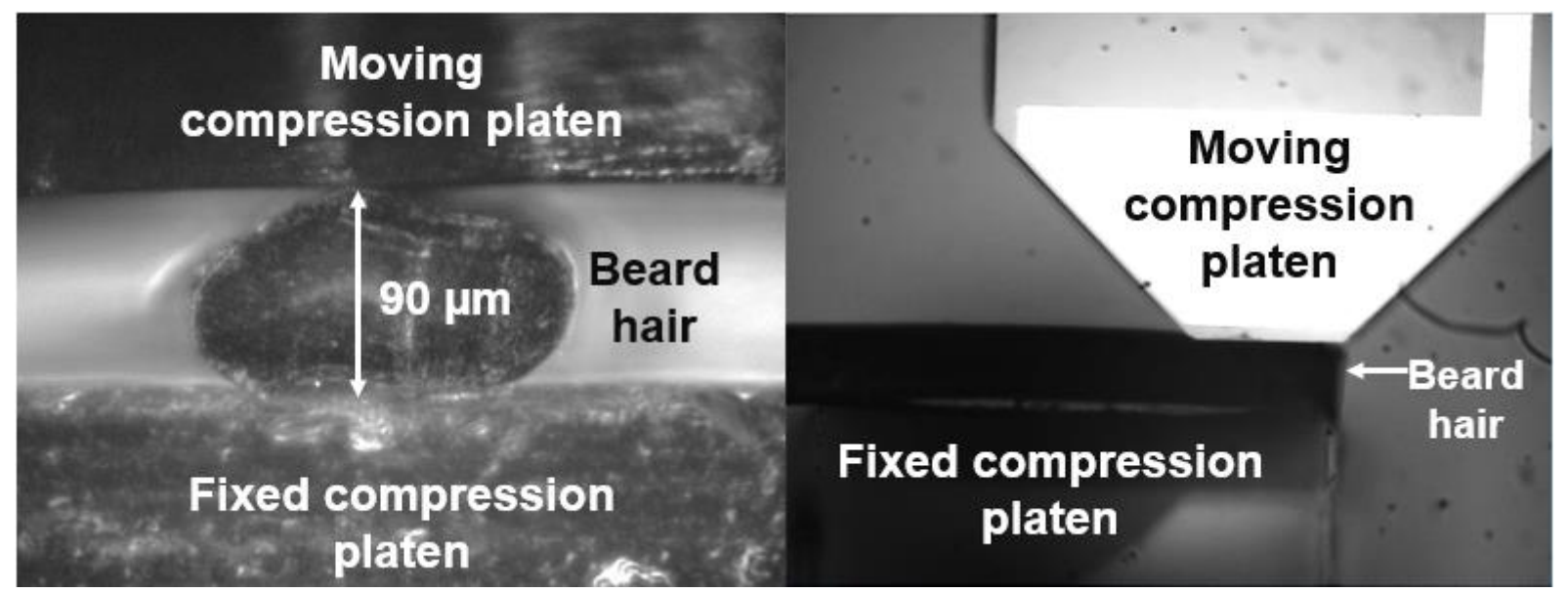

Fig. 8. Transverse compression test on a beard hair
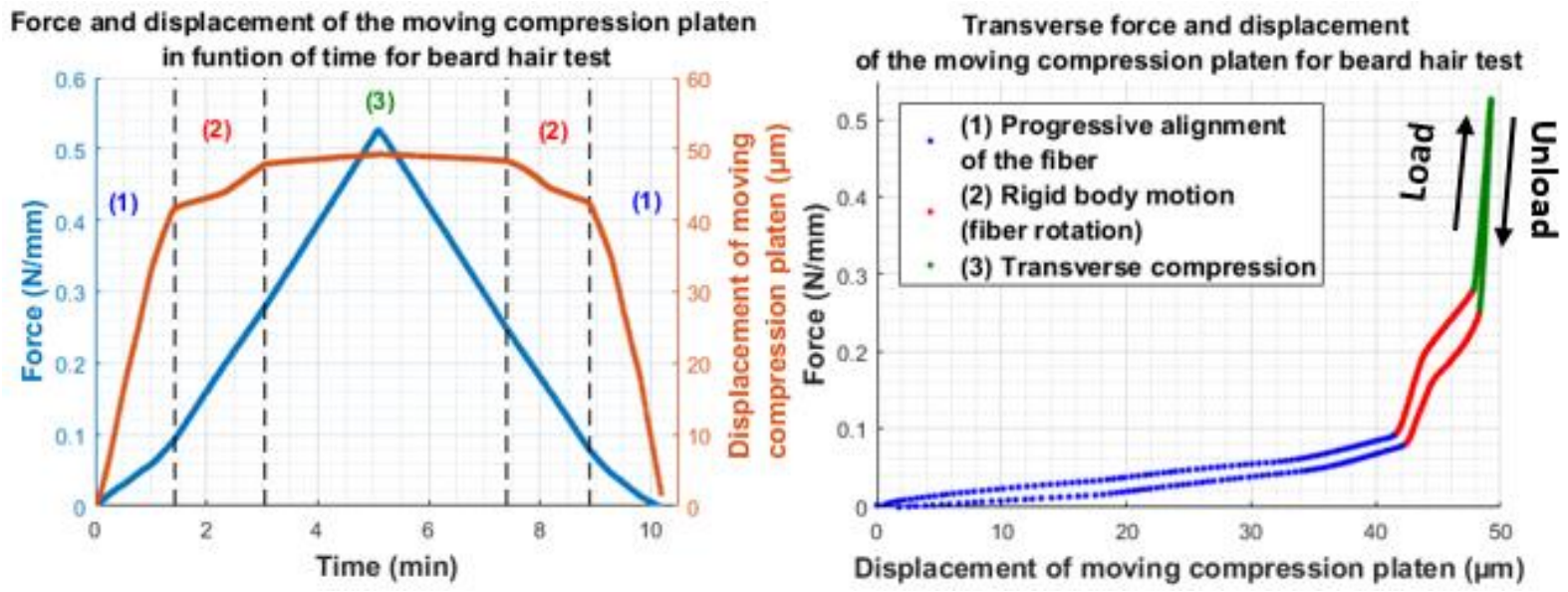

Fig. 9. Experimental results obtained on a beard hair. Left: Force and displacement as a function of time. Right: Force-displacement curve.

Compressive tests were also realized on sisal technical fibers (also called bundle of fibers). These ones are made of few tens of small individual fibers with a thin wall and a large lumen. The tested fibers have a width comprised between 100 and $200 \mu \mathrm{m}$ (Fig. 10). For these fibers, to better take into account their time-dependent behavior, a loading path including a plateau at the maximum load was included. The relaxed properties can then be determined from the un-load phase (Fig. 11). As for the beard hair, a three-stage response was observed. A transverse compressive stiffness of $0.316 \mathrm{~N} \cdot \mathrm{mm}^{-1} \cdot \mu \mathrm{m}^{-1}$ was measured during the unloading step. 


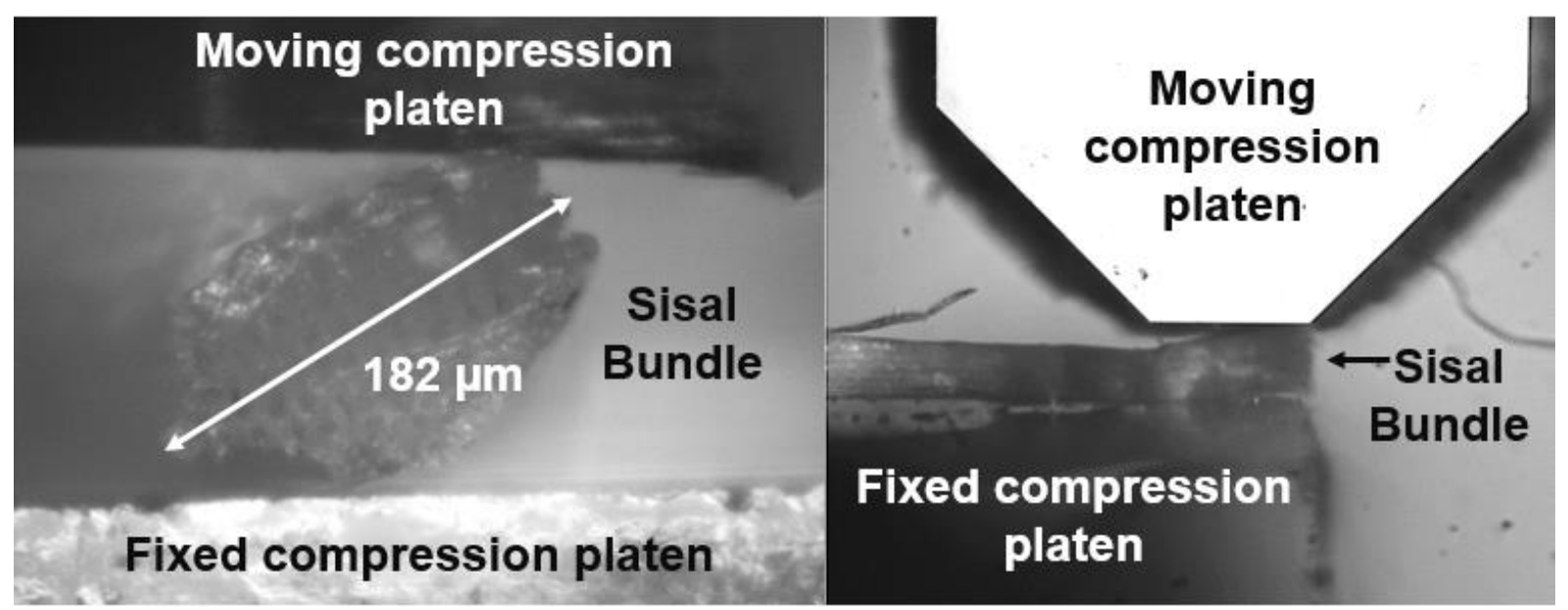

Fig. 10. Transverse compression test on a sisal technical fiber.

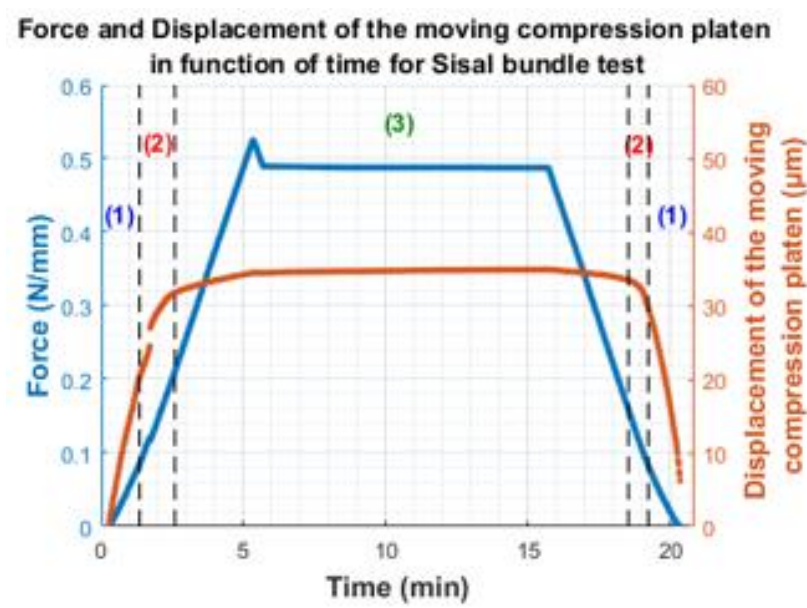

Transverse Force and Displacement of the moving compression platen for Sisal bundle test

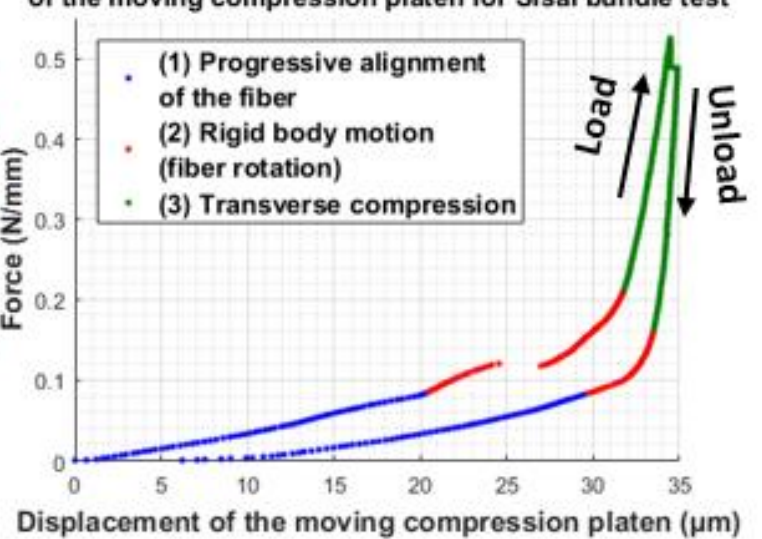

Fig. 11. Experimental results obtained on a sisal fiber bundle. Left: Force and displacement as a function of time. Right: Force-displacement curve.

At this stage, the apparent compressive stiffness of such natural fibers has been successfully determined. The next step is to use the full-field measurements and models adapted to their complex geometry and heterogeneity to determine their intrinsic properties.

\section{Conclusions}

At first, a synthetic monofilament (PA11), already characterized in the literature has been tested to verify and validate the proposed method for the characterization of the transverse compressive properties of micrometric fibers. The values we report for this case study match well with the literature data, validating the relevancy of our approach. An extra information obtained in this study is also the interest of the FBTT test when compared to the SFTT. Indeed, a major requirement to identify the transverse modulus is to know the longitudinal modulus. This value is generally 
obtained after time consuming SFTT experiments. We proposed here a comparison of the values obtained from these two tests. FBTT is arguably interesting in the sense it leads to comparable values while saving time. Our investigation showed also an unexpected scattering of the PA11 tensile properties in general, questioning the monofilament microstructure and also its hypothetic isotropy.

Once the MEMS device performance and interest validated with the PA11, additional tests were performed with more complex fiber structures by using natural fibers. To do so, an animal fiber (mostly proteins-made) of rather large dimensions, a human beard was tested. With a diameter of approximately $140 \mu \mathrm{m}$, the MEMS system has proofed its adequacy. For enlarging the panel of natural fibers, a higher scale of structural complexity was also considered. Technical fibers from sisal were successfully tested. A transverse compressive stiffness of approximately 0.315 N.mm ${ }^{-}$ ${ }^{1} . \mu \mathrm{m}^{-1}$ was measured for both.

\section{Acknowledgements}

The authors gratefully acknowledge the financial support provided by the 'ANS $\mu$ Reshape' received from the CEPIA Science for Food and Bioproduct engineering department of INRA. The works have been also partially funded by the COLAMIR project (contract "ANR-16-CE10-0009"), the EIPHI Graduate school (contract "ANR-17-EURE-0002"),

the Robotex platform (contract "ANR-10-EQPX-44-01"). Authors also acknowledge the French RENATECH network through its FEMTO-ST technological facilities MIMENTO

\section{References}

[1] C. Baley, Y. Perrot, F. Busnel, H. Guezenoc, P. Davies, Mater Lett 60(24) (2006) 2984-2987.

[2] D.W. Hadley, I.M. Ward, J. Ward, Proc. R. Soc. London A (1965) 275-286.

[3] S. Abdul Jawad, I.M. Ward, J Mater Sci 13 (1978) 1381-1387.

[4] J. Wollbrett - Blitz, S. Joannès, R. Bruant, C. Le Clerc, M. Romero De La Osa, A. Bunsell, A. Marcellan, J. Polym. Sci. Part B: Polym. Phys. 54 (2016) 374-384.

[5] V. Guelpa, G. J. Laurent, P. Sandoz and C. Clévy, Trans. on Mechatronics (2015), 20(6).

[6] V. Guelpa, J. S. Prax, Y. Vitry, O. Lehmann, S. Dehaeck, P. Sandoz, C. Clévy, N. Le Fort-Piat, P. Lambert and G.J. Laurent, Int. Conf. on Int.Mech., 2017.

[7] N.I. Muskhelishvili, Some Basic Problems of Mathematical Theory of Elasticity, Noordroof, Holland, 1953.

[8] A. Hansen, P.C. Hemmer and S. Pradhan. The fiber bundle model. Modeling failure in materials. Wiley, 2015.

[9] S.L. Phoenix, J. Skelton, Text Res J (1974) 934-940.

[10] G. Stamoulis, C. Wagner-Kocher, M. Renner, J Mater Sci 42 (2007) 4441-4450.

[11] W. Garat, S. corn, N. Le Moigne, J. Beaugrand, A. Bergeret, Compos PartA 108 (2018) 114-123.

[12] A. Bourmaud, J. Beaugrand, D. Shah, V. Placet, C. Baley, Prog Mater Sci 97 (2018) 347-408

[13] V. Placet, J. Méteau, L. Froehly, R. Salut, L. Boubakar, J Mater Sci 49 (2014) 8317-8327. 